\title{
Passive thermography for delamination detection in GFRP of Wind Turbine Blade
}

\author{
by Lucas REOCREUX ${ }^{a, b}$, Zhewei YU , Sébastien ARNOULD ${ }^{b}$, and Hervé PRONa
}

\author{
a, Université de Reims, ITheMM/Thermique, Campus du Moulin de la Housse BP 1039, 51687 Reims Cedex2, \\ herve.pron@univ-reims.fr \\ b, SupAirVision, 2 rue Gustave Effel, 10430 Rossière-près-Troyes, zy@supairvision.com
}

\section{Abstract}

Wind turbine blade (WTB) is a complex composite structure, which is normally composed of coating (gelcoat), glass fibre reinforced polymer (GFRP), and natural fibres like balsa [1]. During its manufacturing and its service, many types of defects can appear, either surficial or internal, such as cracks, voids, wrinkles, corrosion, delamination, etc. These defects not only can affect the energetic efficiency of the wind turbine, but also can create significant damage and reduce its lifetime. Hence, an appropriate regular inspection is often required. Common inspections in the industry are achieved either by rope access or by telescope from the ground. While such visual inspections cannot detect the internal defect within the WTB, non-destructive testing (NDT) is often applied, such as ultrasonic testing [2] or thermography [3], [4].

In this work, the passive thermography method is tested to determine the delamination in the main laminate area of the WTB. Such an inspection can be achieved by using natural heating sources like sunshine. A thermal contrast is created between a defect area and a normal area while exposing to the sun, which becomes detectable in thermograms taken by infrared cameras. In laboratory, the delamination was approached by the flat bottom holes (FBHs) and by the insert of Bubble Wrap (BW) inside the GPRP. Both numerical modelling and experimental test were carried out in order to evaluate this method.

The experimental test was carried out using a cut piece of a blade with 2 BW inserts with $20 \mathrm{~mm}$ in diameter 7 , $10 \mathrm{~mm}$ in depth as well as 4 flat bottom holes (FBHs) with $20 \mathrm{~mm}$ in diameter and 3, 5, 8, $10 \mathrm{~mm}$ in depth. An impact damage is also presented in the front surface of the sample. At the beginning of the test, this sample was moved from inside (room temperature at $25^{\circ} \mathrm{C}$ ) to outside under the sun irradiation. The thermograms were taken routinely every 4 minutes from 0 to 32 minutes. The result (Fig. 1) shows that the less deep defects, the $3 \mathrm{~mm} F B H$ and the $7 \mathrm{~mm}$ BW insert can be observed easily at early time, which is about 5 minutes. The deeper ones, on the other hand, can be only observed afterwards. However, the maximal thermal contrasts for these defects are generally achieved around 15 minutes, despite the nature, the size or the depth of the delamination defect.

The numerical model is built in order to calculate heat transfer within a coating + GFRP composite structure with different delamination depth for both FBHs and BW inserts. A constant heating source of $300 \mathrm{~W}$ [5] is added to simulate the sunshine, and a convection $\left(h=15 \mathrm{~W} \mathrm{~m}^{-2} \mathrm{~K}^{-1}\right)$ is used to simulate the wind blow. The results for FBHs and BW inserts are presented in Fig. 2 and Fig. 3, respectively. From these figures, it can be seen that the thermal contrast is created once the sun starts heating the sample. The maximum temperature differences as well as the time to reach these differences are presented in Table 1. The maximum temperature difference is reached by some time, and this time is correlated with the defect type and the depth. After these times, the thermal contrasts decrease and become less detectable. It can be concluded that the deeper the defect is, the longer time is required to wait for this maximal temperature difference to appear. Generally, these times are between 5 to 15 minutes, which correspond well the experimental results. These results are also comparable to those reported by Worzewski et al. [6].

Both numerical and experimental results show that the passive thermography inspection for delamination detection can be very useful to detect delamination defect within GFRP. However, this method can be very time dependant, which is also reported in the literature [4], [6].

\begin{tabular}{|l|l|l|}
\hline \multicolumn{2}{|l|}{$\max \boldsymbol{\Delta T}\left({ }^{\circ} \mathbf{C}\right)$} & time (min) \\
\hline FBH (mm) & 3.1 & 6 \\
\hline 3 & 1.8 & 8 \\
\hline 5 & 1.1 & 11 \\
\hline 8 & 0.8 & 16 \\
\hline 10 & 1.8 & 4 \\
\hline BW insert (mm) & 1.1 & 7 \\
\hline 7 & \multicolumn{2}{|l|}{} \\
\hline 10 &
\end{tabular}

Table 1: The maximum thermal contrasts reached with the time for FBHs and BW inserts within GFRP composite, according to the numerical modelling. 

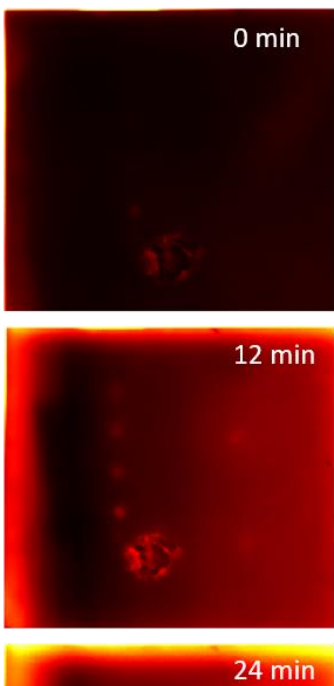

$24 \mathrm{~min}$
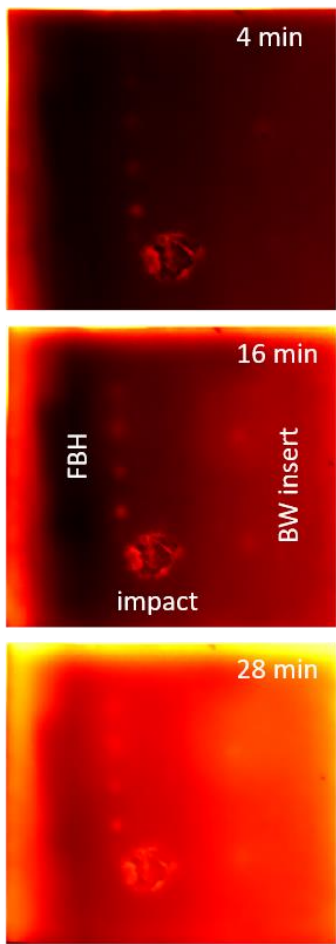
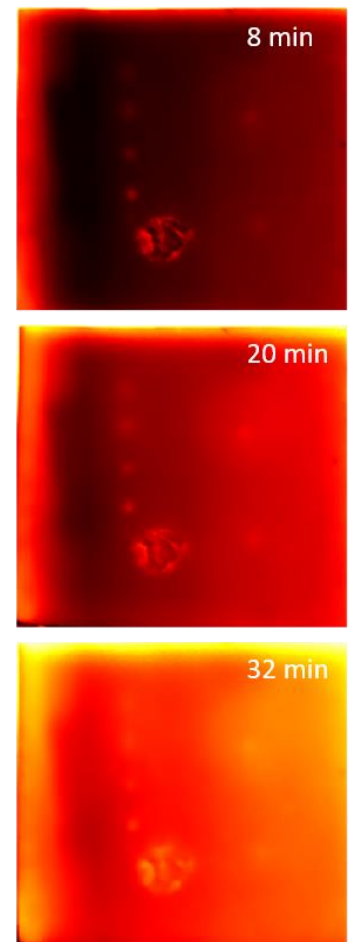

Fig. 1: Thermograms taken of the sample exposed to the sunshine from 0 to 32 minutes. The sample presents a surface impact, 2 BW inserts at 10 and $7 \mathrm{~mm}$ from bottom to top, as well as 4 flat bottom holes (FBHs) with depth 3, 5, 8 and 10 $\mathrm{mm}$ from bottom to top.

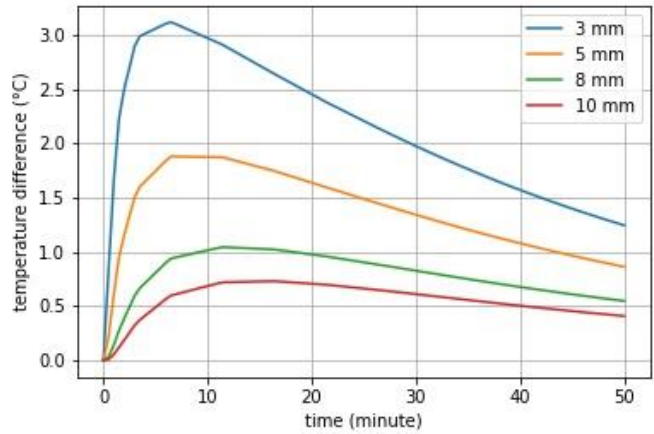

Fig. 2: Numerical modelling result of thermal contrasts created by sunshine with different FBH depths, namely, 3, 5, 8 and $10 \mathrm{~mm}$ along the time, compared to the background.

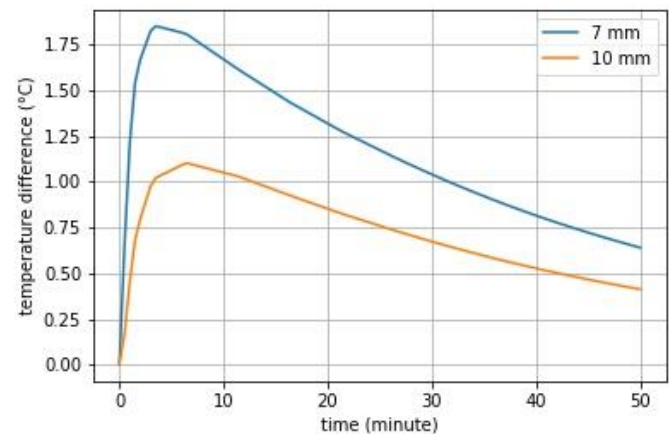

Fig. 3: Numerical modelling result of thermal contrasts created by sunshine with different BW insert depths, namely, 7 and $10 \mathrm{~mm}$ along the time, compared to the background. 


\section{REFERENCES}

[1] L. Mishnaevsky, K. Branner, H. Petersen, J. Beauson, M. McGugan, and B. Sørensen, "Materials for Wind Turbine Blades: An Overview," Materials, vol. 10, no. 11, p. 1285, Nov. 2017.

[2] S. Li, K. Shi, K. Yang, and J. Xu, "Research on the defect types judgment in wind turbine blades using ultrasonic NDT," IOP Conf. Ser. Mater. Sci. Eng., vol. 87, p. 012056, Jul. 2015.

[3] M. Szwedo and P. Hellstein, "Qualitative diagnostics of wind-turbine blades inspection using active thermography," in Proceedings of the 2014 International Conference on Quantitative InfraRed Thermography, 2014.

[4] H. Sanati, D. Wood, and Q. Sun, "Condition Monitoring of Wind Turbine Blades Using Active and Passive Thermography," Appl. Sci., vol. 8, no. 10, p. 2004, Oct. 2018.

[5] T. Worzewski, R. Krankenhagen, M. Doroshtnasir, M. Röllig, C. Maierhofer, and H. Steinfurth, "Thermographic inspection of a wind turbine rotor blade segment utilizing natural conditions as excitation source, Part I: Solar excitation for detecting deep structures in GFRP," Infrared Phys. Technol., vol. 76, pp. 756-766, May 2016.

[6] T. Worzewski, R. Krankenhagen, and M. Doroshtnasir, "Thermographic inspection of wind turbine rotor blade segment utilizing natural conditions as excitation source, Part II: The effect of climatic conditions on thermographic inspections - A long term outdoor experiment," Infrared Phys. Technol., vol. 76, pp. 767-776, May 2016. 